\title{
Occupational Noise Exposure of Traffic Enforcers in Selected Streets in the City of Manila
}

\author{
Louise Elinor R. Dulay, ${ }_{1}^{1}$ Ma. Danica Katrina P. Galvan, ${ }^{1}$ Rio Joana M. Puyaoan, ${ }^{1}$ \\ Angel Abraham Y. Sison, ${ }^{1}$ Nicole S. Natanauan ${ }^{1}$ and Paul Michael R. Hernandez ${ }^{2}$ \\ ${ }^{1}$ College of Public Health, University of the Philippines Manila \\ ${ }^{2}$ Department of Environmental and Occupational Health, College of Public Health, University of the Philippines Manila
}

\begin{abstract}
Objective. The study aimed to evaluate the sound pressure levels of selected traffic enforcer sites in the City of Manila.

Methods. A Brüel \& Kjær Integrating Sound Level Meter type 2225 was used to measure sound pressure levels in $\mathrm{dB}(\mathrm{A})$ to estimate personal noise exposure of traffic enforcers designated at Quezon Boulevard near Quiapo Church and Recto - Rizal Avenue on a weekday and a weekend. Graphs were generated while appropriate measures were calculated for the noise exposure levels. The mean exposure levels were compared with the Philippine Occupational Safety and Health standards by computing the corresponding permissible exposure limit for each work shift using the Equal Energy Principle. ${ }^{17}$
\end{abstract}

Results. Noise exposure levels at Quezon Boulevard ranged from $75.0 \mathrm{~dB}(\mathrm{~A})$ to $91.5 \mathrm{~dB}(\mathrm{~A})$ with mean noise exposure level of $84.3 \pm 3.7 \mathrm{~dB}(\mathrm{~A})$ and $82.5 \pm 2.6 \mathrm{~dB}(\mathrm{~A})$ for the weekday $\mathrm{AM}$ and $\mathrm{PM}$ shift, respectively. The mean noise exposure level at Quezon Boulevard for the weekend AM shift was $82.4 \pm 2.6$, whereas $80.4 \pm 2.8$ for the PM shift. The noise exposure levels at Recto - Rizal Avenue ranged from $81.5 \mathrm{~dB}(\mathrm{~A})$ to $99.3 \mathrm{~dB}(\mathrm{~A})$ with mean noise exposure level of $86.7 \pm 2.6 \mathrm{~dB}(\mathrm{~A})$ and $86.0 \pm 2.1 \mathrm{~dB}(\mathrm{~A})$ for the weekday $\mathrm{AM}$ and $\mathrm{PM}$ shift, respectively. The mean noise exposure level at Recto - Rizal Avenue for the weekend AM shift was $86.7 \pm 2.3$, whereas $89.0 \pm 4.0$ for the PM shift.

Conclusion. The study showed that traffic enforcers designated at Quezon Boulevard and Recto - Rizal Avenue are exposed to noise levels that do not exceed the Philippine Occupational Safety and Health standards.

Key Words: occupational noise, traffic enforcers, occupational health and safety, occupational noise exposure, industrial hygiene

\section{INTRODUCTION}

Noise is an unwanted and unpleasant sound ${ }^{1}$ that can disrupt individuals' activity and deteriorate their quality of life by affecting how they normally function - psychologically, physiologically or socially. ${ }^{2}$ It can be classified into either occupational or environmental noise. Occupational noise includes all unwanted sounds in the workplace while environmental noise comes from all sources of noise excluding those that are from the workplace. ${ }^{3-4}$ Exposure to noise can be affected by the following factors: intensity of noise (sound pressure level), frequency distribution of the noise, time pattern and duration of exposure..$^{5}$ As the levels of these factors increase, the greater is the damage that can be inflicted on the exposed individual. ${ }^{6}$

In order to limit noise exposure of individuals in

Corresponding Author: Louise Elinor R. Dulay College of Public Health University of the Philippines Manila

625 Pedro Gil Street Ermita, Manila 1000 Philippines

Mobile Phone: +639453381635

Email: Irdulay@up.edu.ph the environment and workplace, standards have been developed by different institutions such as World Health Organization (WHO), United States Environmental Protection Agency (US EPA) and Occupational Safety and 
Health Administration (OSHA). In the Philippines, the institutions that set the standards include the Department of Health (DOH) and the Occupational Safety and Health Center (OSHC) under the Department of Labor and Employment (DOLE).

Awareness on pollution brought about by noise has always been limited due to its unnoticeable effects but recently, noise is becoming a more prominent social, environmental and health problem due to the increasing urbanization. ${ }^{1-2,6}$ Road traffic, one of the dominant sources of noise in urban and rural environment, continuously rises with the increasing number of people and vehicles, as well as congestion of traffic. ${ }^{7}$ Traffic enforcers, who spend most of their time in roads directing traffic, are at the forefront of exposure to road traffic noise.

A study on the noise exposure among traffic police officers conducted in Sudan reported that the noise levels measured using a dosimeter were high at all points which in turn have led to annoyance and tinnitus among the traffic enforcers. ${ }^{8}$ Worse effect, such as hearing loss, may also be induced by occupational noise exposure according to the audiometric results of the study conducted among French motorcycle police officers. ${ }^{9}$ Despite the alarming health effects of traffic noise exposure, there are however no published studies in the Philippines that focus on this subject. ${ }^{10}$

In line with this pressing concern, this study aimed to evaluate the noise exposures of traffic enforcers in selected streets in the City of Manila, Philippines to act as a guide for the formulation and implementation of control measures designed to protect these workers from the harmful health effects of occupational noise. This study specifically intended to describe the weekday and weekend sound pressure levels of selected traffic enforcer sites and to compare the sound pressure levels to the Philippine Occupational Safety and Health $(\mathrm{OSH})$ standards.

\section{METHODS AND MATERIALS}

A descriptive study design was used to measure the sound pressure levels of selected traffic enforcer sites in the City of Manila for the estimation of the noise exposure of the traffic enforcers in these areas.

\section{Study Population}

The study population was composed of traffic enforcers employed by the Manila Traffic and Parking Bureau (MTPB) of the City of Manila. Specifically, traffic enforcers who: (1) worked from 6:30AM - 12:00PM or 12:30PM - 7:00PM, or within these specified time in the selected busiest streets of Manila from the list provided by MTPB; ${ }^{11}$ (2) were permanently assigned to the area; (3) did not frequently leave their posts except for restroom breaks; and (4) have consented to participate in the study. They were not characterized according to age, sex, and years of employment because noise exposure levels are independent of these variables.
MTPB $^{11}$ specified eight streets in Manila that are considered busiest in terms of vehicular and pedestrian volume among all areas where the traffic enforcers are deployed. These sites are: Divisoria (Recto - Abad Santos), Lawton (Park and Ride), Quezon Boulevard in front of Quiapo Church, Quirino, Ramon Magsaysay Boulevard (Ramon Magsaysay V. Mapa), España - Lacson, Recto - Rizal Avenue, and Taft Avenue (United Nations Ave. - Kalaw).

An ocular survey was conducted to identify the study sites. Criteria for choosing these included the following: (1) noise levels as perceived by the MTPB; (2) if the traffic enforcers stay on the site throughout their entire shift; and (3) safety considerations of the investigators (e.g. being hit by vehicles). Only two sites qualified for the study: Quezon Boulevard in front of Quiapo Church and Recto - Rizal Avenue.

\section{Preliminary Assessment}

Preliminary assessment was done on the two selected streets to identify the sampling points where traffic enforcers are positioned. The different sources of noise present in the area such as trains, vehicles, people, and construction activities were identified but were not quantified.

\section{Estimating Personal Noise Exposure}

Participants were first briefed about the study and the content of the informed consent form at their outposts before the start of their shift and the actual data collection.

Upon consultation with the OSHC DOLE regarding the methodology, ${ }^{12}$ the investigators used an analog integrating sound level meter (Brüel \& Kjær Integrating Sound Level Meter type 2225) to measure sound pressure levels (in $\mathrm{dB}(\mathrm{A})$ ) at selected traffic enforcer sites. To account for variations in noise intensities throughout the monitoring period, readings were taken using the slow response setting of the sound level meter. ${ }^{13}$

In measuring occupational noise exposure, the recommendations set forth by OSHA of the United States Department of Labor ${ }^{14,15}$ were employed. The sound level meter was calibrated using a Brüel \& Kjær Sound Level Calibrator type 4230 prior to data collection. The instrument's microphone was positioned within the hearing zone of the traffic enforcer, which is around two feet diameter surrounding the head of the enforcer ${ }^{14}$ (refer to Figures 1 and 2).

Readings were taken for one minute at 10-minute intervals for the entire shift (5.5 hours for morning and 6.5 hours for afternoon); hence, the number of measurements was expected to be 33 recordings in the AM shift and 39 recordings in the PM shift. Since the analog integrating sound level meter displays sound pressure levels instantaneously, a video camera was used to record the readings generated by the integrating sound level meter during the 1-minute measurement. Data collection in each street was done for two days, Monday or Friday, and Saturday, which were identified as busy days by OSHC. ${ }^{12}$ Table 1 shows the dates on which the measurements were taken. 
Table 1. Noise measurement, shift duration and number of readings according to site and day, City of Manila, December 2013

\begin{tabular}{|c|c|c|c|c|}
\hline Site & \multicolumn{2}{|c|}{ Weekday } & \multicolumn{2}{|c|}{ Weekend } \\
\hline \multirow{2}{*}{ Quezon Boulevard } & \multicolumn{2}{|c|}{$12 / 13 / 2013$ (Friday) } & \multicolumn{2}{|c|}{$12 / 14 / 2013$ (Saturday) } \\
\hline & Shift duration (hours) & No. of readings & Shift duration (hours) & No. of readings \\
\hline AM Shift & 5.5 & 29 & 5.5 & 32 \\
\hline PM Shift & 6 & 32 & 6.67 & 38 \\
\hline \multirow{2}{*}{ Recto - Rizal Avenue } & \multicolumn{2}{|c|}{ 12/16/2013 (Monday) } & \multicolumn{2}{|c|}{$12 / 28 / 2013$ (Saturday) } \\
\hline & Shift duration (hours) & No. of readings & Shift duration (hours) & No. of readings \\
\hline AM Shift & 4.17 & 25 & 4.58 & 27 \\
\hline PM Shift & 5.67 & 34 & 5.17 & 29 \\
\hline
\end{tabular}

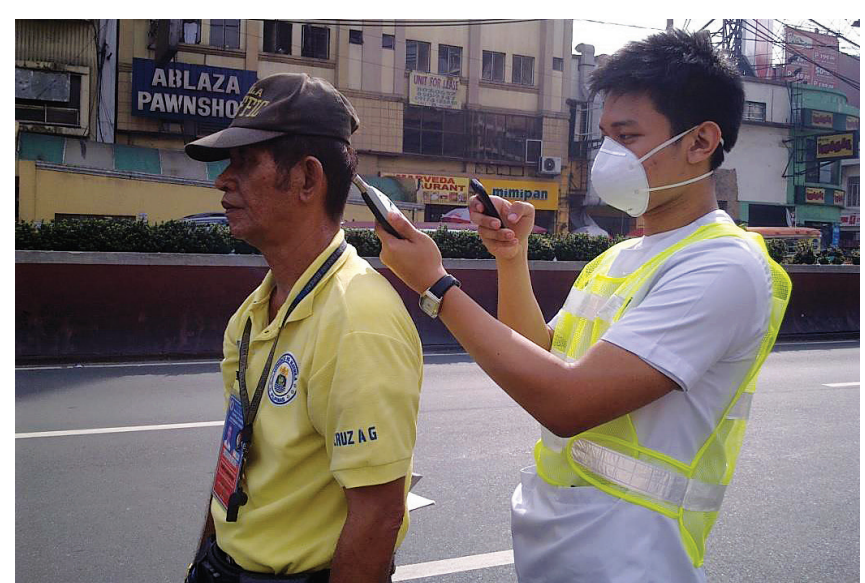

Figure 1. Noise Exposure Measurement, Quezon Boulevard, Manila, Philippines, December 2013.

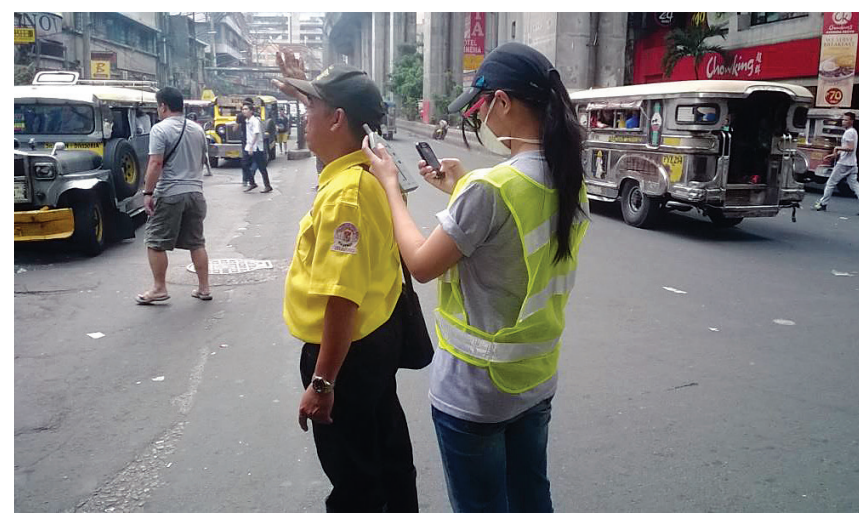

Figure 2. Noise Exposure Measurement, Recto-Rizal Avenue, Manila, Philippines, December 2013.

Safety precautions such as wearing of masks and reflective vests, keeping close to the traffic enforcer, and crossing the street only when the green light is on for pedestrians were observed by the investigators during data collection.

\section{Data Processing and Analysis}

The videos of the recorded measurements were viewed by the investigators to determine the highest and lowest values of each 1-minute measurement. There were non-continuous levels of noise in the area while measuring the noise exposure of the traffic enforcers hence the arithmetic average of the highest and lowest values obtained during the 1-minute measuring time was computed.
To account for variations in the duration of noise measurements, the mean exposure levels were compared with the Philippine $\mathrm{OSH}^{16}$ standards by computing the corresponding permissible exposure limit for each work shift using the Equal Energy Principle ${ }^{17}$ equation

Limit for a given shift $=L_{\text {exposure limit }}-10 \log \frac{T}{8}$,

where $T$ is the hours of shift and $L_{\text {exposure limit }}$ is the standard value.

Using Microsoft Excel 2013, graphs were generated to present the sound pressure levels of the sites for each day. All the values obtained for a workshift (AM/PM) of a specific site (Quezon Boulevard/ Recto - Rizal Avenue) for each day of measurement were utilized to compute for the mean, standard deviation, and range of the noise level to which traffic enforcers were exposed to. Furthermore, the mean levels were compared to the Philippine OSH Standards.

\section{Ethical/Biosafety clearance}

Ethical clearance was provided by the College of Public Health Ethics Review Board.

\section{RESULTS}

The sites selected for the study were the portion of Quezon Boulevard in front of Quiapo Church, and Recto - Rizal Avenue. Upon initial survey of the study sites, the investigators noted that the sources of noise at Quezon Boulevard were the vehicular traffic, the traffic enforcers' whistling, the numerous parishioners attending mass in Quiapo Church, the priest's sermon blaring from the public address system stationed outside the church, and the vendors and commuters present in the area. In Recto - Rizal Avenue, aside from the vehicles and whistles, noise sources include the music being played outside the malls, shouting pedestrians and barkers of jeepneys, and the trains that were plying the overhead railways. In both study sites, there were instances that the investigators had to speak louder in order to hear each other.

During the data collection, the rumbling from an outside broadcasting vehicle's generator added to the noise produced by the sources initially identified at Quezon Boulevard. In Recto - Rizal Avenue, on the other hand, there were more noise sources present than previously noted - sidewalk 
vendors were blowing air horns (torotot) throughout the shift, shops were playing Christmas songs more frequently and loudly, a mass of people was joining a protest demonstration going to Mendiola, and fire engines and ambulances with their blaring sirens were passing through Recto - Rizal Avenue to respond to an emergency.

There was a total of nine traffic enforcers who were eligible to participate but only seven enforcers were included in the study. Two traffic enforcers were excluded because they did not give consent to join the study.

Only one enforcer was enrolled for each shift during both days of data collection in each study site. The enforcers assigned at Quezon Boulevard directed traffic at the middle of the road, near the side entrances of the church, and at the flyover going to Quiapo Bridge. In Recto - Rizal Avenue, the enforcers performed their duties at the middle of the intersection and at an area near the sidewalk where jeepneys are likely to pick up passengers.

The noise exposure levels for both days in each site showed no conclusive trends throughout the entire AM and PM shifts. The readings at Recto - Rizal Avenue were higher compared to the Quezon Boulevard readings (see Figures 3 and 4).

As seen in the graphs, the shift duration varied between days and sites. This is also shown in Table 1 . The shift duration of the traffic enforcers ranged from 4.17 to 6.67 hours while the corresponding number of readings ranged from 25 to 38 .

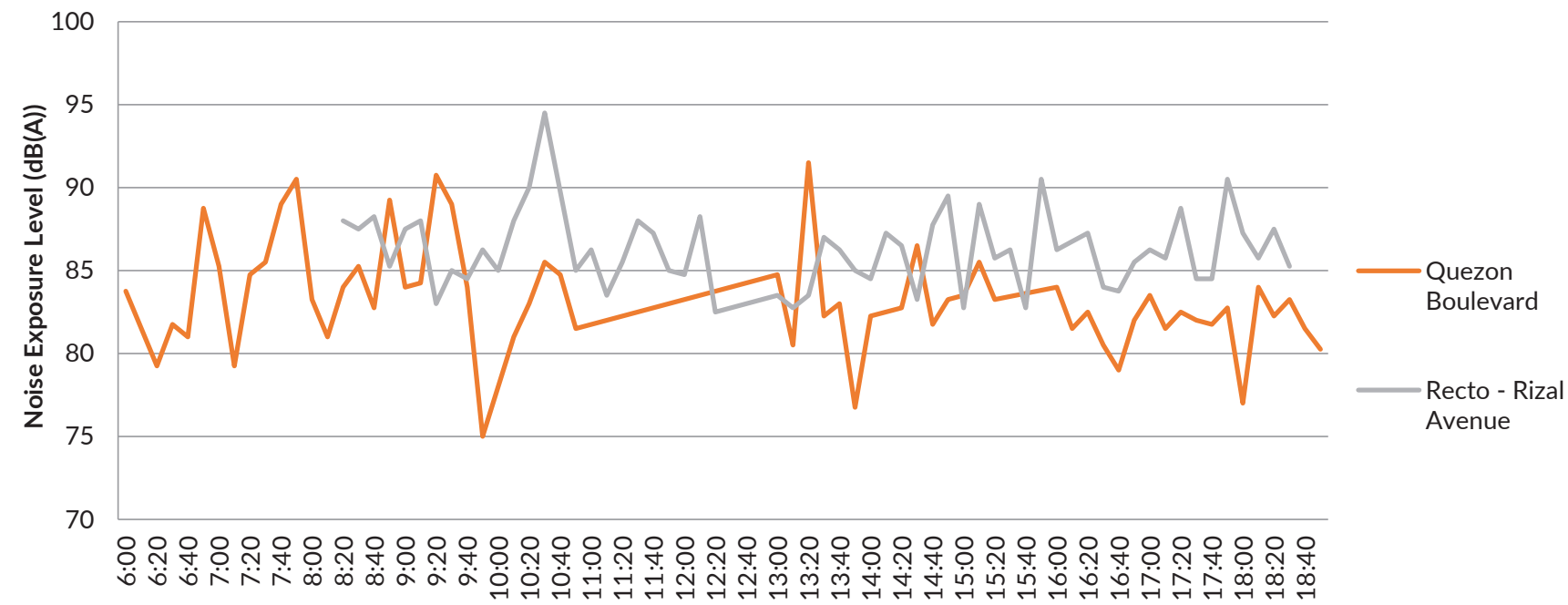

Time(24-hour)

Figure 3. Noise exposure levels of weekday AM and PM shifts in Quezon Boulevard and Recto - Rizal Avenue, City of Manila, December 2013.

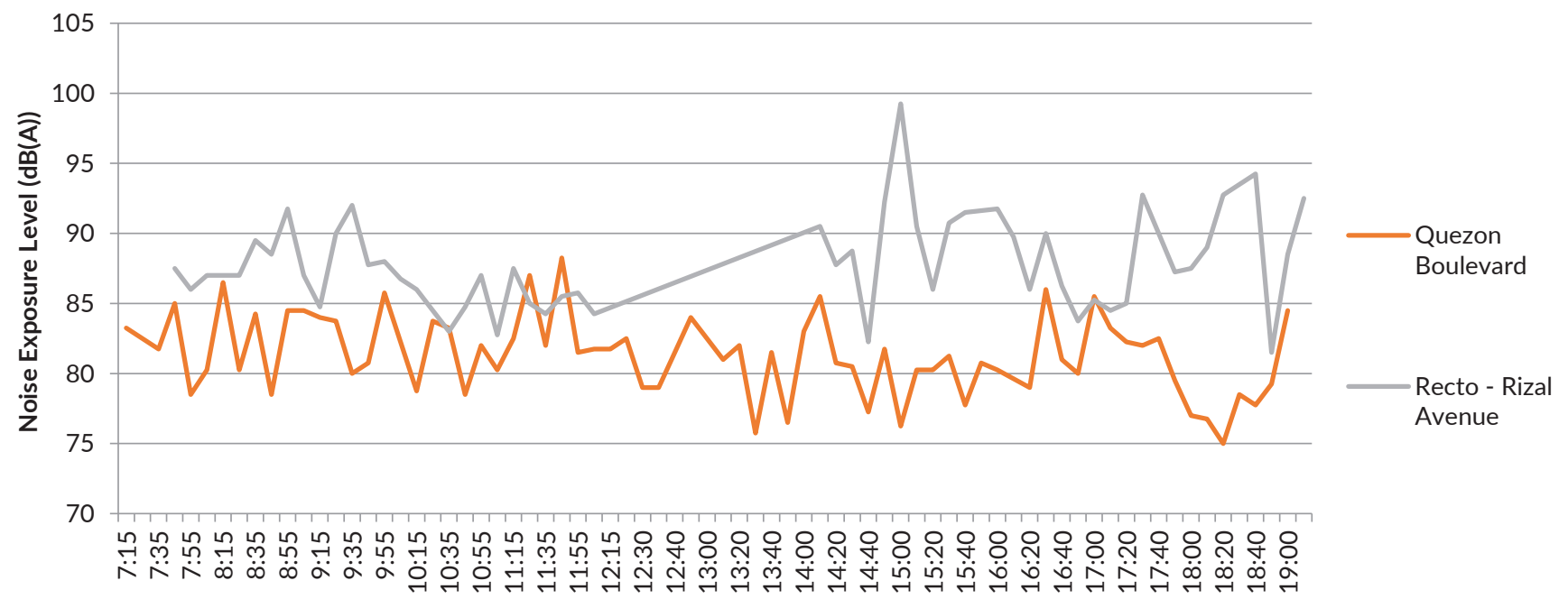

Time (24-hour)

Figure 4. Noise exposure levels of weekend AM and PM shifts in Quezon Boulevard and Recto - Rizal Avenue, City of Manila, December 2013. 
Table 2. Mean, maximum and minimum sound pressure levels according to site, day and shift, City of Manila, December 2013

\begin{tabular}{|c|c|c|c|c|c|}
\hline Site & Day & Shift & $\bar{x} \pm s$ & $\operatorname{Max} .(\mathrm{dB}(\mathrm{A}))$ & $\operatorname{Min} .(d B(A))$ \\
\hline \multirow{4}{*}{ Quezon Boulevard } & \multirow{2}{*}{ Weekday } & AM & $84.3 \pm 3.7$ & 90.8 & 75.0 \\
\hline & & PM & $82.5 \pm 2.6$ & 91.5 & 76.8 \\
\hline & \multirow{2}{*}{ Weekend } & AM & $82.4 \pm 2.6$ & 88.3 & 78.5 \\
\hline & & PM & $80.4 \pm 2.8$ & 86.0 & 75.0 \\
\hline \multirow{4}{*}{ Recto - Rizal Avenue } & \multirow{2}{*}{ Weekday } & AM & $86.7 \pm 2.6$ & 94.5 & 82.5 \\
\hline & & PM & $86.0 \pm 2.1$ & 90.5 & 82.8 \\
\hline & \multirow{2}{*}{ Weekend } & AM & $86.7 \pm 2.3$ & 92.0 & 82.8 \\
\hline & & PM & $89.0 \pm 4.0$ & 99.3 & 81.5 \\
\hline
\end{tabular}

Table 3. Interpretation of the mean noise exposure level according to site, shift and day, City of Manila, December 2013

\begin{tabular}{|c|c|c|c|c|c|c|c|}
\hline Site & Day & Shift & $\begin{array}{c}\text { Mean Noise } \\
\text { Exposure Level }\end{array}$ & $\begin{array}{l}\text { Computed } \\
\text { POSH PEL }\end{array}$ & Interpretation & $\begin{array}{l}\text { Computed } \\
\text { NIOSH REL }\end{array}$ & Interpretation \\
\hline \multirow{4}{*}{$\begin{array}{l}\text { Quezon } \\
\text { Boulevard }\end{array}$} & \multirow{2}{*}{ Weekday } & AM & 84.3 & 92.2 & Within limits & 87.2 & Within limits \\
\hline & & PM & 82.5 & 91.8 & Within limits & 86.8 & Within limits \\
\hline & \multirow{2}{*}{ Weekend } & AM & 82.4 & 91.8 & Within limits & 86.8 & Within limits \\
\hline & & PM & 80.4 & 91.0 & Within limits & 86.0 & Within limits \\
\hline \multirow{4}{*}{$\begin{array}{l}\text { Recto-Rizal } \\
\text { Avenue }\end{array}$} & \multirow{2}{*}{ Weekday } & AM & 86.7 & 92.8 & Within limits & 87.8 & Within limits \\
\hline & & PM & 86.0 & 91.5 & Within limits & 86.5 & Within limits \\
\hline & \multirow{2}{*}{ Weekend } & AM & 86.7 & 92.5 & Within limits & 87.5 & Within limits \\
\hline & & PM & 89.0 & 92.2 & Within limits & 87.2 & Greater than permissible limits \\
\hline
\end{tabular}

The noise exposure levels of traffic enforcers ranged from 75.0 to $99.3 \mathrm{~dB}(\mathrm{~A})$. The mean noise exposure levels measured at Recto - Rizal Avenue were higher compared to the levels in Quezon Boulevard. Mean noise exposure levels during the weekend at Recto - Rizal Avenue were higher than its weekday measurements. This was contrary to the averages in Quezon Boulevard where the weekday mean was higher compared to that of the weekend (see Table 2).

The mean exposure levels were compared with the Philippine OSH standards by computing the corresponding permissible exposure limit (PEL) for each work shift using the Equal Energy Principle (see equation (1)). Philippine OSH PELs were computed based on the specific duration of exposure of each traffic enforcer. All the noise exposure levels of the traffic enforcers in Quezon Boulevard and Recto-Rizal Avenue were within permissible exposure limits (see Table 3).

\section{DISCUSSION}

The results of this study showed that there were variations in the noise exposure levels of traffic enforcers. At Quezon Boulevard near Quiapo Church, noise exposure levels ranged from $75.0 \mathrm{~dB}(\mathrm{~A})$ to $91.5 \mathrm{~dB}(\mathrm{~A})$; whereas, in Recto-Rizal Avenue, the levels ranged from $81.5 \mathrm{~dB}(\mathrm{~A})$ to $99.3 \mathrm{~dB}(\mathrm{~A})$. These variations may be attributed to the different kinds of noise sources in the study sites and the changing intensities of noise they produce. Both have huge vehicular volume and establishments surrounding the areas but Recto-Rizal Avenue is a busier area (an intersection compared to a street) with trains plying the overhead railways. In both study sites, there were instances that the investigators had to speak louder in order to hear each other.

Fajardo et $\mathrm{al}^{2}$ in 1999 measured noise level values in other busy streets in the City of Manila such as Taft Avenue, where levels ranged from $76 \mathrm{~dB}(\mathrm{~A})$ to $83 \mathrm{~dB}(\mathrm{~A})$, and Quirino Avenue, where levels ranged from $67 \mathrm{~dB}(\mathrm{~A})$ to $77 \mathrm{~dB}(\mathrm{~A})$. The maximum and minimum values recorded in the said study were lower than those obtained in this study. These disparities may be due to the difference in study sites, which have varying noise sources. It may also be attributed to the increased number of registered vehicles in the National Capital Region and the increased population in the City of Manila. ${ }^{18}$

In other countries, there were also studies that evaluated the noise exposure among traffic enforcers designated in busy streets. In the cross-sectional study by Sliman, et $\mathrm{al}^{8}$ in Khartoum (Sudan) locality roads, the noise exposure levels ranged from $74.5 \mathrm{~dB}(\mathrm{~A})$ to $86.7 \mathrm{~dB}(\mathrm{~A})$. Meanwhile, in the study of Leong et $\mathrm{al}^{19}$ in 2003 in various traffic zones of Bangkok Metropolitan Region, the noise levels measured ranged from $72.8 \mathrm{~dB}(\mathrm{~A})$ to $83.0 \mathrm{~dB}(\mathrm{~A})$ during day time, and $59.5 \mathrm{~dB}(\mathrm{~A})$ to $74.5 \mathrm{~dB}(\mathrm{~A})$ during night time. It can be noted that the maximum and minimum values of noise exposure levels in both aforementioned international studies were lower than those recorded at Quezon Boulevard and RectoRizal Avenue. Furthermore, the noise exposure levels obtained among traffic policemen in Jalgaon City in the study of Ingle et $\mathrm{a}^{20}$ in 2005 ranged from $79.9 \mathrm{~dB}(\mathrm{~A})$ to $95.4 \mathrm{~dB}(\mathrm{~A})$. These values are higher than the minimum and maximum values obtained at Quezon Boulevard, but still lower than those obtained at Recto-Rizal Avenue.

Aside from the differences in the range, variations in the computed mean exposure levels between days of data collection were also evident. As shown in Table 2, the mean noise exposure levels of traffic enforcers in Quezon Boulevard for both shifts of the weekday were higher than those of the weekend. This may be due to the larger volume of people attending mass on the selected weekday for data collection that resulted to heavier traffic; thus, more noise sources and greater noise intensities. On the other hand, for Recto - Rizal 
Avenue, the mean noise exposure levels measured for both shifts on the weekday were lower compared to the levels obtained during the weekend. Possible reason is the increased number of people going to the malls within the vicinity during weekends which contributed to the higher noise levels in the area.

Moreover, upon analysis of the results using the Philippine OSH standards, all the noise exposure levels of the traffic enforcers in Quezon Boulevard and Recto-Rizal Avenue were all within permissible limits. This is based on the comparison of the mean exposure levels with the Philippine OSH standards through the computation of the corresponding permissible exposure limit for each work shift using the Equal Energy Principle ${ }^{17}$.

Since OSHA, from which the Philippine $\mathrm{OSH}$ standards of OSHC - DOLE was based, recognizes that a number of its permissible exposure limits are outdated and may be insufficient in ensuring that workers are not exposed to dangerous levels of physical hazards such as noise, ${ }^{21}$ comparison with standards from other institutions such as the National Institute for Occupational Safety and Health (NIOSH) were also considered. The comparison was done by computing the corresponding recommended exposure limit (REL) for each work shift using the Equal Energy Principle. The noise exposure levels of all shifts at both sites are all within their computed RELs except for the weekend PM shift of Recto - Rizal Avenue. This entails the demand for proper hearing protection for the traffic enforcers designated in this particular shift.

The sets of standards issued by OSHC - DOLE, OSHA, and NIOSH are not absolute values and therefore should not be considered as strict boundaries between levels that are safe from possibly deleterious outcomes and levels that can cause adverse health effects. Compliance with the Philippine OSH Standards does not automatically mean that the traffic enforcers are safe ${ }^{22}$. There are other factors that can increase their susceptibility in developing NIHL, such as co-exposure to ototoxic agents - solvents, heavy metals, tobacco smoke which may act in synergy with noise to cause hearing loss. ${ }^{23}$

Some biases, although tried to be minimized, may still have been introduced. One of these was the limited number of days on which data were collected. Also, the recordings obtained did not completely show all noise levels for the whole work shift since there was a ten-minute interval between measurements. Furthermore, meteorological conditions during the data collection were a source of variation in measurements that cannot be controlled due to the inherent limitation of the sound level meter. More importantly, only estimation of personal exposure was conducted. Additional monitoring strategies, which include personal noise dosimetry, area noise monitoring, and health surveillance will increase the strength of evidence in establishing noise exposure levels and its health effects. ${ }^{24}$

In conclusion, the study has established that traffic enforcers who work in the AM and PM shifts at Quezon
Boulevard and Recto - Rizal Avenue are exposed to noise levels that do not exceed the Philippine OSH standards; but further analysis showed that noise levels during the weekend PM shift in Recto - Rizal Avenue exceeded NIOSH RELs.

Further studies that would use additional monitoring and assessment strategies are warranted to determine if the occupational noise exposures of the traffic enforcers are excessive and detrimental to health. It is also recommended to increase sample size and study sites to improve external validity of the study. Lastly, the employers of the traffic enforcers are advised to apply administrative controls, such as (1) education and elevation of awareness of traffic enforcers on noise and its potential health impacts; (2) conduction of baseline audiometry before deployment and every 3 years thereafter to monitor any adverse effects of noise to the traffic enforcers' hearing; (3) implementation of job rotation wherein traffic aides are required to rotate for a significant number of hours (e.g. 4 hours of an 8-hr shift) in less noisy sites within the day, to reduce the traffic enforcer's risk of developing NIHL.

\section{Acknowledgments}

The researchers would like to express their gratitude to: Mr. Carter Don Y. Logica, the officer-in-charge, and Mr. Narciso Diokno III, the chief for operations, of Manila Traffic and Parking Bureau, and the sector leaders and traffic enforcers deployed in Quezon Boulevard and Recto-Rizal Avenue; Engr. Rene N. Timbang, officer of the Environmental and Occupational Health Office of the Department of Health; Dr. Marissa L. San Jose, supervising occupational health officer, and Engr. Melba F. Marasigan, senior industrial hygienist, of the Occupational Safety and Health Center of the Department of Labor and Employment; PH 197/199 Committee chaired by Prof. Teresita S. de Guzman; and the Department of Environmental and Occupational Health of the College of Public Health.

\section{Statement of Authorship}

All authors have approved the final version submitted.

\section{Author Disclosure}

All authors have declared no conflict of interest.

\section{Funding Source}

No external funding.

\section{REFERENCES}

1. Vergel KN, Cacho FT, and Capiz CLE. A study on roadside noise generated by tricycles. Philippine Journal of Engineering 2004; 25(2):1-22.

2. Fajardo, B. A study on individual perceptions of road traffic. MA thesis. School of Urban and Regional Planning, University of the Philippines Diliman;1999. pp.1-21.

3. Concha-Barrientos M, Campbell-Lendrum D, and Steenland K. Occupational noise: Assessing the burden of disease from 
work-related hearing impairment at national and local levels. Geneva: World Health Organization (SWTZ); 2004. 33 p. Report No.: WHO Environmental Burden of Disease Series, No. 9.

4. Berglund, B., Lindvall, T., and Schwela, D. (eds.) Guidelines for community noise. [Online] Geneva: World Health Organization; 1999. p57. Available from: http://www.who.int/docstore/peh/ noise/Comnoise-4.pdf [Accessed 21st May 2014]

5. Johnson, D.L., Papadopoulos, P., Wafta, N. and Takala, J. Exposure criteria, Occupational exposure levels. [Online] Geneva: World Health Organization; 1995. p81. Available from: http://www.who.int/occupational_health/publications/noise4. pdf [Accessed 21st May 2014].

6. Singh, V.K., and Mehta, A.K. Prevalence of Occupational noiseinduced hearing loss amongst Traffic Police Personnel. IJO \& HNS [Online] 1999; 51(2): 23-26. Available from: http://www. ncbi.nlm.nih.gov/pmc/articles/PMC3451516/ [Accessed 21st May 2014].

7. Hagler, L., and Goiner, L. Noise pollution: a modern plague. Southern Medical Journal. [Online] 2007; 100(3):287-293. Available from: http://www.nonoise.org/library/smj/smj.htm [Accessed 21st May 2014].

8. Sliman A, Ibrahim O, Ahmed A. Noise exposure among traffic police officers in Khartoum Locality, Sudan. European Scientific Journal (2015); 11(6):131-5

9. Lesage, F., Jovenin, N., Deschamps, F., and Vincent, S. Noiseinduced hearing loss in French police officers.Occupational Medicine. [Online] 2009; 59: 483-486. Available from: doi: 10.1093/ocmed/kqp091

10. Shrestha I., Shrestha BL., Pokhael M., Amatya RCM., and Karki DR. Prevalence of noise-induced hearing loss among traffic police personnel of Kathmandu Metropolitan Police. Kathmandu University Medical Journal. [Online] 2011; 9(36): 274-278. Available from: http://www.kumj.com.no/issue/36/274-278.pdf.

11. Diokno III, N. Chief of operations, Manila Traffic \& Parking Bureau, City of Manila. Personal communication. 5 Nov 2013.

12. Occupational Safety and Health Center. Rules and Regulations Implementing Executive Order No. 307 Establishing an Occupational Safety and Health Center in the Employees' Compensation Commission. [Online] Available from: http:// www.oshc.dole.gov.ph/122/ [Accessed 21st May 2014]

13. Pelton, H. Noise control management. New York, New York: Van Nostrand Reinhold. 1993; p.131.

14. Occupational Safety and Health Administration. Appendix III: A. instruments used to conduct a noise survey. [Online] Available from: http://www.osha.gov/dts/osta/otm/noise/ exposure/instrumentation.html [Accessed 21st May 2014].

15. Occupational Safety \& Health Administration United States Department of Labor. Appendix III:B. General sampling protocol. [Online] 1991. Available from: http://www.osha. gov/dts/osta/otm/noise/exposure/workshift_protocol.html [Accessed 21st May 2014]
16. Occupational Safety and Health Administration. OSHA 1910.95. Permissible Noise Exposures - Annotated Tables [Online]. Available from: https://www.osha.gov/pls/oshaweb/owadisp. show_document?p_table=STANDARDS\&p_id=9735 [Accessed 21st May 2014].

17. Lester H, Malchaire J, Arbey H, Thiery H. Strategies for Noise Surveys. Occupational exposure to noise: evaluation, prevention, and control. 1st ed. Geneva: World Health Organization; 2001; pp.141-182.

18. Astrera M. Statistical Reports [Online]. Lto.gov.ph. 2016 [cited 4 May 2016]. Available from: http://www.lto.gov.ph/publication/ statistical-reports

19. Leong SLaortanakul P. Environmental Monitoring and Assessment. 2003;85(1):69-85.

20. Ingle S, Pachpande B, Wagh N, Patel V, Attarde S. Assessment of Daily Noise Exposure and Prevalence of Hearing Loss in the Shopkeepers Working Near National Highway No. 6: A Case Study of Jalgaon City. International Journal of Sustainable Transportation. 2009;3(1):54-69.

21. Occupational Safety \& Health Administration. Permissible Exposure Limits - Annotated Tables. [Online]. Available from: https://www.osha.gov/dsg/annotated-pels/ [Accessed 21st May 2014].

22. Spellman FR. and Bieber RM. Environmental Health and Science Desk Reference. [Online] Maryland: Government Institutes; 2012. p596. Available from: http://books.google.com. ph/books?id=0_rz4HbovcsC\&pg=PA596\&lpg=PA596\&dq=acgi $\mathrm{h}+\mathrm{tl} \mathrm{v}+\mathrm{absolute}+\mathrm{values} \&$ source $=$ bl\&ots $=6 \mathrm{r} 27 \mathrm{XWoM} 3 \mathrm{O} \&$ sig $=\mathrm{Ye}$ UHC39EyQrIp2r10298L9aO53U\&hl=en\&sa=X\&ei=ONTXUrm iEIiVkgXL3oGoAQ\&ved=0CDsQ6AEwCQ\#v=onepage\&q=ac gih\%20tlv\%20absolute\%20values\&f=false [Accessed 21st May 2014].

23. The American College of Occupational and Environmental Medicine. Noise-induced Hearing Loss [Online]. Journal of Occupational and Environmental Medicine. 2003. pp579-581. Available from: http://journals.lww.com/joem/ Fulltext/2003/06000/Noise_induced_Hearing_Loss.1.aspx [Accessed 21st May 2014].

24. Safe Work Australia. Health Monitoring for Exposure to Hazardous Chemicals: Guide for Persons Conducting a Business or Undertaking. [Online] Australia: Safe Work Australia; 2013. p6. Available from: http://www.safeworkaustralia.gov.au/sites/ SWA/about/Publications/Documents/754/Guide-PCBU-HealthMonitoring-Exposure-Hazardous-Chemicals.pdf [Accessed 21st May 2014]. 